\title{
KNOWLEDGE MANAGEMENT IN MANUFACTURING: THE SOFT SIDE OF KNOWLEDGE SYSTEMS
}

\author{
Ove R. Hjelmervik, Kesheng Wang \\ Department of Production and Quality Engineering, Norwegian University of Science and \\ Technology, 7495 Trondheim, Norway
}

\begin{abstract}
Organizational learning is important for a firm's productivity growth. According to some literature, information and communication technology (ICT) do not support organizational learning and therefore not enhanced productivity. This research has demonstrated that in the case of manufacturing companies some computer-based systems do support organizational learning.
\end{abstract}

Key words: Knowledge Management, Knowledge Management System, Organizational learning, Manufacturing.

\section{INTRODUCTION}

There is much discussion about knowledge management (KM) and knowledge management systems (KMS), but mostly conceptually or consultatively. It is a common belief that KMS can be a source for strengthening an enterprise's knowledge, but little evidence is provided on the issue of information technology's impact on effectiveness or efficiency in business firms (Nonaka et al, 2001; Brynjolfsson and Hitt, 1998). Some literature (Brown and Duguid, 1991; Corley and Gioia, 2003) argues that learning takes place where practice is executed, in a master-apprentice relationship. We will in this research investigate if, and under which circumstances, a KMS can support a firm's routine development and thus enhance value creation (Huber, 1991). This is of primary importance for a firm in the way it does business. As the world is changing it is important for

Please use the following format when citing this chapter:

Hjelmervik, Ove, R., Wang, Kesheng, 2006, in International Federation for Information Processing (IFIP), Volume 207, Knowledge Enterprise: Intelligent Strategies In Product Design, Manufacturing, and Management, eds. K. Wang, Kovacs G., Wozny M., Fang M., (Boston: Springer), pp. 89-94. 
firms to participate in its development. Knowledge management in a manufacturing context is a firm's ability to empower employees to enact reiterating processes between employees, technology and organization, leading to organizational learning. Our case study, in progress, describes the way two production sights within an aluminum company (ALU) apply its KMS, called Best Practice System (BPS). The study tries to identify why changing from the old to the new system made an influence on employees' support for organizational learning, as they apply computer technology in their everyday activities,. This paper will explore the use of ICT on organizational learning as the organization changes from one system to another. The data collection takes place in the period 2002 through 2005.

\section{THE CASE}

In year 2000 ALU's management decided to restructure the organization from a hierarchical to a processual structure. Today, the business process consists of three main activities: upstream activities (Primary Metal Sector), midstream activities (Metal Products Sector), and downstream activities (here represented by its Automotive Sector). Each Sector manager reports to the CEO. This restructuring resulted in fewer organizational layers. Management decided on the following strategy: more of the operational responsibilities to self-managed teams, and introduction of Best Practice to be aligned with Key Performance Indicators. The employee empowerment required changes to the information availability and structure. One of the important issues for management was an ICT capability allowing employees to transfer experience, process such experience and distribute it as new best practice. In 2003 the old system, SDOCS, was gradually replaced by the new system BPS, previously described in Wang et al (2001). The installation took place in the period 2003-2004. This longitudinal study reaches over a period of three years. The old system was a Lotus Note based document handling system, bringing up complete documents representing many separate routines. No supportive documentation, such as drawings, pictures or video could be attached, a capability the new system has. Furthermore, each document was restructured to bring up issue/task-specific routines linked into the value chain. At each task-specific routine one can encode and transfer an experience back to the process owner.

The Best Practice document structure (figure 1) installed in the global aluminum company has the following structure: User-interface business processes and system processes. Drill-down into the different process segments reveal sub-processes, flow chart and individual work activities with links to relevant documents. Furthermore, each work activity has an "experience transfer" button linking the relevant activity to the process 

systems

owner. There is also a search engine for internal and external document search, based on "intelligent agents" technology. The technology structure for the business system can be seen from Fig. 2 .

Management has provided the self-managed work teams with access to relevant information, routines tools and resources to carry out, and thus optimizing, the operating process. At any point along the production line a self-managed work team is responsible for a production segment. They also have to know what activity is upstream and downstream of the segment. By opening an electronic work activity page, the employee can see who is responsible for delivering what into the team's operating segment, its expected quality and timing of the delivery. Likewise, the electronic work activity page will tell the team who the customer is, what delivery responsibility the team has, the quality and timing of the delivery.

The business system is a KM system open to all employees. It is passive, except for the Intelligent Agent, and subsequently does not process data for intelligent analysis. From here you can reach all operational systems. These systems can be line-of-business application such as human resource systems, incident registration system "Synergy", enterprise resource planning system "SAP", or a document management system "Domino Doc" (Fig. 3). In order for employees to search on key words, concepts, etc., the system has an intelligent agent technology installed in the Oracle server. The agent is aiding the user by interacting with internal and external databases and the Oracle Knowledge Server. Figure 3 illustrates how interaction between databases and intelligent agent technology is aided by the Knowledge Server. The end result is served through the web server and out to the client.

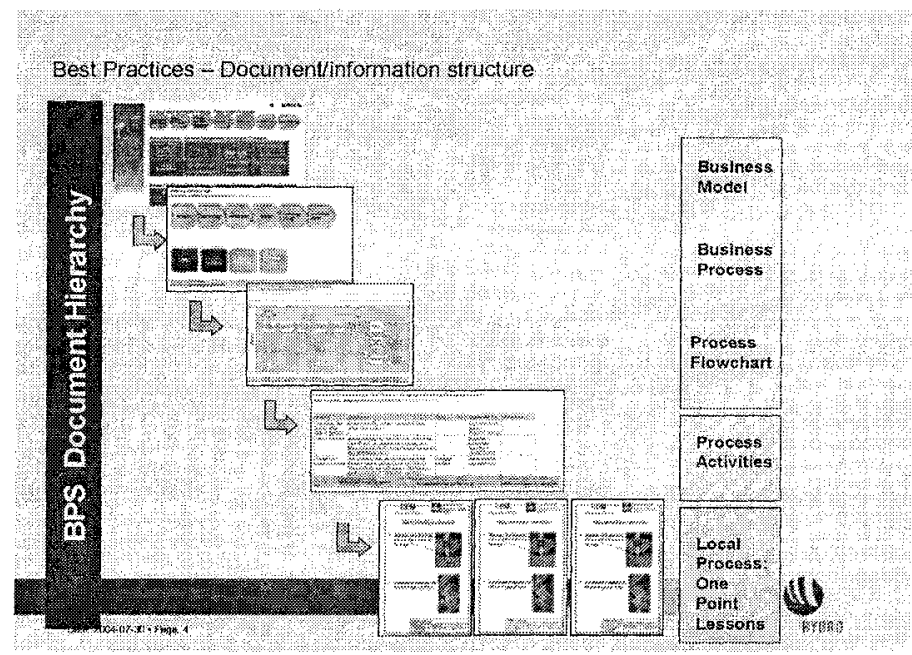

Figure 1 Best Practice document structure in BPS 

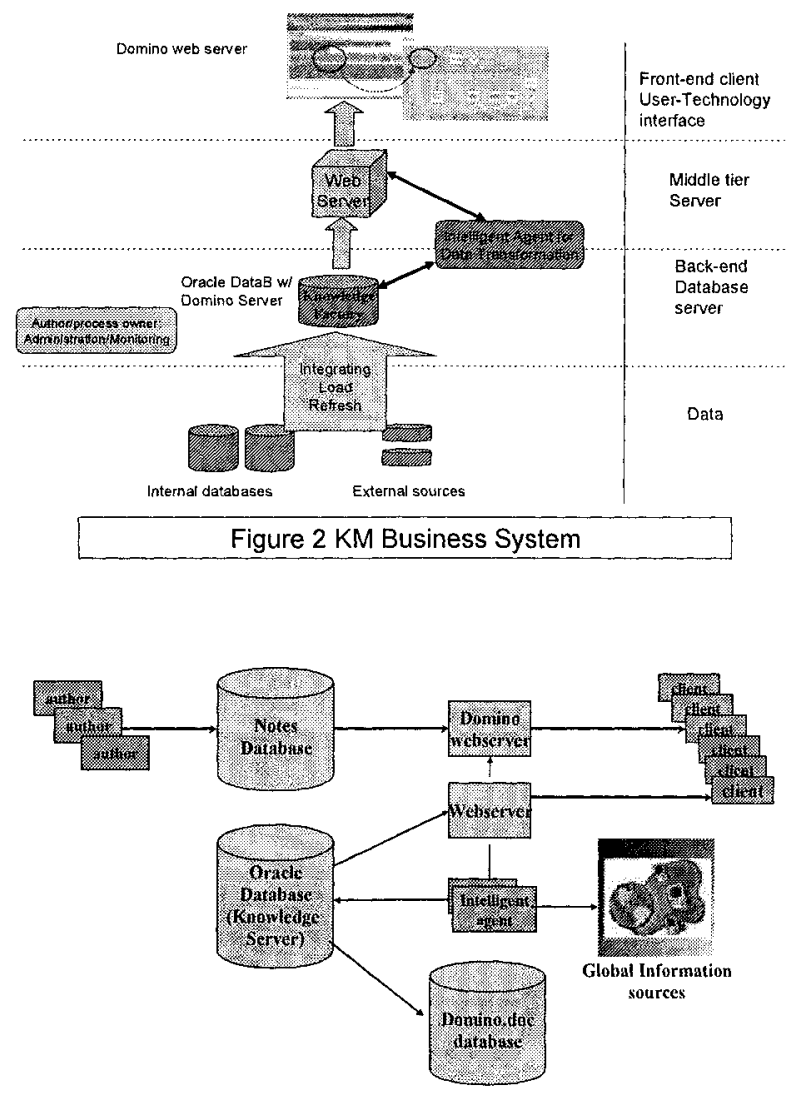

Figure 3 BPS Technical architecture

ALU's KMS is a directional and task related process system, supporting operational (production and staff) activities in mowing goods from raw materials to finished products, in a partly closed and partly open production.

\section{REPORT FINDINGS}

Knowledge management has something to do with learning, and since we associate management with organizations we consider knowledge management as part of organizational learning (Levitt and March, 1988). Furthermore, as learning is something you do to improve a current routine for the purpose of changing the institutional rules, values and processes, it is 

systems

important for the firm to develop dynamic capabilities (Zollo and Winter, 2002). Such capabilities come from the organization's ability to learn, and develop, new routines in a reiterating process between employees, technology and organization. Such reiteration process can be understood in relation to structuration theory (Orlikowski, 1992).

We wanted to understand if a computer based business system could support organizational learning, and under which circumstances. Based on two plant location, and a set of nested levels of interviews from senior management to production operators, we found Zollo and Winters' knowledge evolution cycle to be reflecting the organization's dynamic capability, that is: variation, selection, replication and retention; and their three levels of learning mechanisms: experience accumulation, knowledge articulation and knowledge codification. Linking such dynamic capabilities to Orlikowski's (1992) expanded structuration theory, we found that in order for knowledge management to take place in the organization, all levels of the organization must participate. Management must allow dynamic capabilities to develop, employees must be encouraged to participate in organizational learning, and decision-making powers must be transferred to teams. Such strategy includes three elements: empowerment; a technology to represent organization knowledge; and employee participation in developing new or improved routines leading to enhanced productivity.

\section{CONTRIBUTION}

There is much discussion about knowledge management (KM) and knowledge management systems (KMS), but mostly conceptually or consultatively. Little evidence is provided on the issue of information technology's impact on effectiveness or efficiency in business firms. We found that employees, interacting with technology in their ongoing practices, enact structures which shape their emergent and situated use of that technology (Orlikowski, 2000), leading to participation in the development of product knowledge (Zhang, et al, 2005). This research investigated how KMS can support a firm's routines, process and product development, and thus enhance value creation. We found that organizations learn through empowered enactment, supported by KMS.

Based on this research we have defined KM in a manufacturing context as a firm's ability to empower employees to enact reiterating processes between employees, technology and organization. Furthermore we have defined a KMS as a push-pull technology providing employees with relevant information at point of decision, for the propose of execute current routines 
and processes, and support the development of new or improved routines and processes based on experience, trends and patterns in operating processes.

Further research includes organizational learning, supported by KMS, can lead to enhanced productivity.

\section{CONCLUSION}

We have in this research established that it is possible for a computer system to support organizational learning in manufacturing organizations. It is the way such computer system is structured which makes it valuable for the organization. Empowerment and access, for the purpose of organizational learning, are two important factors for a successful KMS.

\section{REFERENCES}

Brown, J.S., and P. Duguid, (1991), Organizational learning and communities of practice: toward a unified view of working, learning and innovation. Organizational Science, 2.

Brynjolfsson, E., and L.M. Hitt, (1998), Beyond the productivity paradox: computers are the catalyst for bigger changes. Communication of the ACM.

Corley, K.G., and D.A. Gioia, (2003), Semantic learning as change enabler: Relating organizational identity and organizational learning. Handbook of Knowledge Management, Blackwell.

Huber, G.H., 1991, Organizational learning: The contributing processes and the literatures, Organization Science, Vol., 2, No. 1, February.

Levitt, B., and J.G. March, (1988), Organizational Learning; Annual Review of Sociology, 14, pp. 319-340.

Nonaka, I., P. Reinmõlter, and R. Toyama, (2001), Integrated information technology systems for knowledge creation, in Handbook of organizational learning and knowledge, eds.: $\mathrm{M}$. Dierkes, A. B. Antal, J. Child, and I. Nonaka. Oxford University Press, Oxford.

Orlikowski, W. J., (2000) Using Technology and Constituting Structures: A Practice Lens for Studying Technology in Organizations; Organization Science, vol. 11, No. 4, pp. 404428.

Orlikowski, W. J., (1992), The duality of technology: Rethinking the concept of technology in organizations. Organization Science, vol. 3, no. 3.

Wang, K, O.R. Hjelmervik, B. Bremdal, (2001), Introduction to Knowledge Management, theory and practice, Tapir Academic Publisher, Trondheim.

Zhang, J., Wang, Q., Wan, L. and Zhong Y., (2005), Configuration-oriented Product Modeling and Knowledge Management for Made-to-order Manufacturing Enterprises, Int. J Adv Manufacturing Technology, Vol. 25, pp. 41-52.

Zollo, M., and S.G. Winter; (2002), Deliberate Learning and the Evolution of Dynamic Capability, Organization Science, vol. 13, no. 3, p. 339. 